\title{
Habitat-diversity relationships in rocky shore algal turf infaunal communities
}

\author{
Simon F. Thrush ${ }^{1,2, *}$, Mariachiara Chiantore ${ }^{1}$, Valentina Asnaghi ${ }^{1}$, Judi Hewitt ${ }^{2}$, \\ Dario Fiorentino ${ }^{3}$, Riccardo Cattaneo-Vietti ${ }^{1}$ \\ ${ }^{1}$ DipTeRis, Università di Genova, Corso Europa 26, 16132 Genoa, Italy \\ ${ }^{2}$ National Institute of Water and Atmospheric Research, PO Box 11-115 Hillcrest, Hamilton, New Zealand \\ ${ }^{3}$ Laboratory of Zoology and Marine Biology, DiSTeBA, University of Salento, Strada provinciale Lecce-Monteroni, \\ 73100 Lecce, Italy
}

\begin{abstract}
Relationships between habitat complexity and biodiversity are a cornerstone of ecology. On many rocky shores, the cryptic macrofauna that live in the biogenic habitat created by larger organisms adds considerably to biodiversity. Algal turfs are commonly considered to facilitate high species richness of resident organisms by moderating the physically stressful characteristics of the rocky shore. We conducted a multi-scale study to describe scales of patchiness within sites and define the strength of local habitat and broader environmental variables on infaunal turf communities. Species richness contributed by sampling turf dwelling infauna increased our estimates of rocky shore diversity by $>100 \%$ compared to traditional visual quadrat sampling. Generalised linear models of the species density and abundance of infaunal turf organisms and canonical correspondence analysis of community structure did not indicate a strong role for algal turf habitat complexity. Multivariate partitioning was used to assess the importance of processes operating on site and regional scales in influencing the infaunal turf community. The analysis demonstrated the importance of cross-scale relationships and high levels of unexplained variation. Analysis of biological traits demonstrated widely dispersing species were strongly influenced by broad-scale environmental factors. Feeding traits indicated that the infaunal turf community was dominated by species capable of switching strategies between autotrophic and detrital based foodwebs, with the exception of suspension feeding species. Overall, and contrary to previous studies, our results indicate wide niches for infaunal turf species and weak relationships between the infaunal community and turf habitat characteristics. Spatial variation in turf habitat characteristics was not the main driver of spatial variation in turfdwelling organisms, implying that the habitat variability we observed was not strongly influencing physical stresses, such as temperature and wave disturbance.
\end{abstract}

KEY WORDS: Algal turf - Infauna - Diversity-habitat relationships $\cdot$ Biological traits $\cdot$ Spatial scale $\cdot$ Mediterranean Sea

Resale or republication not permitted without written consent of the publisher

\section{INTRODUCTION}

Positive relationships between biodiversity and habitat structure are central to many fundamental ecological issues (e.g. facilitative interactions, the characterisation of niche dimensions) and have important applications in habitat mapping and conservation. Nevertheless, the strength of these relationships and their interaction with broad-scale environmental pro- cesses are often poorly defined (Norkko et al. 2006). Intertidal rocky shore habitats have provided many examples of the interaction of physical and biological processes associated with habitat-biodiversity linkages. Rocky intertidal habitats are physically and biologically stressful environments, with stressful conditions often ameliorated by the resident habitat forming species (Menge \& Sutherland 1987). However, most intertidal research has focused on the large visible and 
relatively sedentary organisms, such as mussels, limpets, barnacles and macroalgae (Kelaher et al. 2001). This ignores the more cryptic but often abundant macrofaunal communities (usually polychaetes and small crustaceans) that live in the biogenic habitat created by the habitat forming organisms. For these macrofaunal organisms, we might expect the amelioration of stressful conditions associated with desiccation and wave stress to be important, with strong relationships between habitat structure and complexity and the diversity and abundance of turf dwelling infauna. These relationships should be evident in spatial patterns unless the rate and spatial scale of mobility blurs the pattern.

On many temperate intertidal shores, algal turfs are often the dominant biogenic habitat, composed of a matrix of small macroalgae mainly belonging to the order of Corallinales, Ceramiales and other green and red filamentous algae. Previous studies have demonstrated that algal turfs can have strong effects on the distribution of macrofaunal organisms that live in the turf matrix (Abbiati et al. 1987, 1991, Giangrande 1988, Sarda 1991, Kelaher et al. 2001). Algal turfs can provide protection from dislocation due to waves, provide shade and restrict the variability in humidity and temperature on the shore (Kelaher et al. 2001, Bulleri \& Benedetti-Cecchi 2008). The turf habitats can also act as a filter to larvae or swimming or drifting adults; thus, increases in the abundance of organism with increasing biogenic habitat complexity could occur due to passive entrapment (Dean \& Connell 1987). Habitat structure provided by turf and larger macroalgae can also provide a refuge from predation by large mobile predators such as fish (Coull \& Wells 1983), although within the turf, some infauna are also predators (e.g. some nereid and syllid polychaetes) and suspensionfeeders can filter settling larvae (Young \& Cameron 1989, Gili \& Coma 1998). These habitat-mediated effects imply that changes in turf habitat structure should influence the diversity of niches available to rocky shore infauna. The reduced environmental stress, the 3-dimensionality of the habitat and the mobility of many turf-dwelling organisms could limit the dominance of space competition as the key process driving community interactions on the rocky shore.

Assessing the importance of regional and local factors in affecting species diversity remains a major challenge in biodiversity research. Marine systems in general, and rocky shore systems in particular, are typically described as open, i.e. characterised by species with broad larval dispersal. However, there is growing evidence for limited connectivity for many marine species due to larval behaviour and the retention of larvae by oceanographic phenomena such as gyres and eddies (Caley et al. 1996, Levin \& Talley
2002, Gilg \& Hilbish 2003, Becker et al. 2007, Rilov et al. 2008, Stevens et al. 2008). Oceanographic variability associated with productivity, wave exposure and disturbance are important drivers of broad-scale patterns that also affect local species interactions (Dayton 1971, Menge et al. 1997). Therefore, any analysis of diversity-habitat relationships across locations should also include the assessment of broader scale physical habitat features. For example, Blanchard \& Bourget (1999) related various aspects of physical heterogeneity of a rocky-shore coastline measured at multiple spatial scales to aspects of benthic community structure (including diversity) and showed that processes operating over different spatial scales best explained different aspects of community structure.

Apart from developing a fundamental understanding of the relationships between biodiversity and habitat structure, there are important implications for habitat mapping, resource management and conservation, as broad-scale, easy to measure, habitat features often act as surrogate variables for community or ecosystem integrity. For example, the definition of habitat quality indicators and the identification of baselines against which ecological change are assessed are important tools for resource managers. In the European Water Framework Directive (WFD) 2000/60/EC, the assessment of water quality is based on ecological status determined for several key biological features including macroalgae. In Mediterranean coastal marine ecosystems, one of the indices (CARLIT) is based on the occurrence and abundance of common upperinfralittoral, macroalgal-dominated communities on rocky shores (Ballesteros et al. 2007, Mangialajo et al. 2007, Asnaghi et al. 2009). Defining the strength of the relationship between broad-scale, easily censused habitat variables and aspects of biodiversity such as species richness are important for both understanding the sensitivity of indicators to change and defining how change in indicator variables relates to broader shifts in biodiversity. For example, Ward et al. (1999) found that habitat level surrogates were useful in an initial identification of marine reserves, but plant assemblages were poor surrogates for overall species richness.

Here we present the results of a multi-scale coastal survey planned to define relationships between the diversity and community structure of intertidal turfdwelling infauna and the habitat structure generated by the larger species. We identified the strength of relationships between infaunal turf community structure, abundance and species density (i.e. number of species per sample) in relation to both local habitat features and broad-scale environmental drivers. To describe scales of patchiness within sites, we analysed spatial structure and looked for correlations between 
species density and abundance relative to biogenic habitat structure. We used multivariate variance partitioning techniques to indicate key drivers that represent the environmental niche dimensions of turf dwelling infauna and assessed the relative importance of local (within site) and regional scale habitat variables. As the strength of habitat-diversity relationships is likely to be affected by the biological traits of resident species, we also performed separate analyses of the mobility traits and feeding types of the turf infaunal community. We expected to find local variables to be more important for species with limited mobility and regional scale variables to be more important for those with highly mobile larval and adult life stages. Species with obligate feeding strategies were expected to be affected by broad-scale variation in resources, while generalist feeders were expected to be evenly distributed because of wider trophic niche dimensions.

\section{MATERIALS AND METHODS}

Sites and sampling. We surveyed 10 sites on the eastern Ligurian Riviera, Italy, extending over $\sim 80 \mathrm{~km}$ of coastline (Fig. 1, Appendix 1). Sampling was conducted in July 2008. Each site consisted of a $150 \mathrm{~m}$ transect located in the shallow infralittoral (at the mean low water level) and looked consistent in terms of rock slope and aspect to open water. Tidal range in this region is low $(30 \mathrm{~cm})$ and waves and wind-driven flows

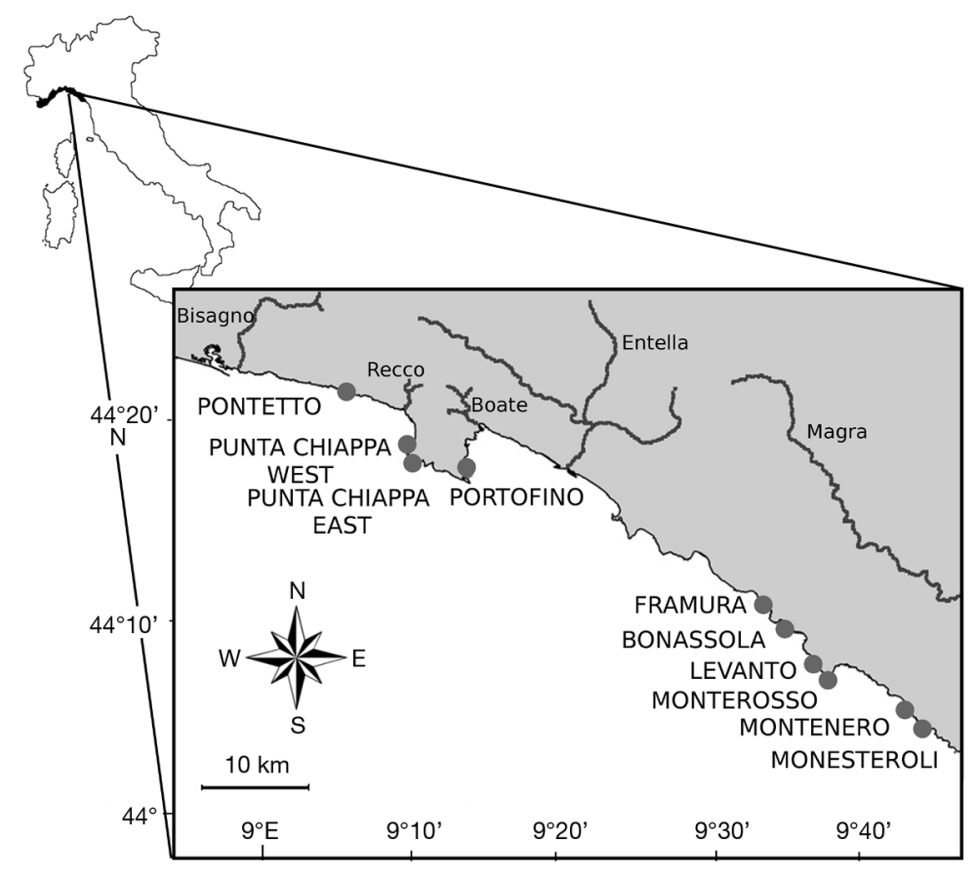

Fig. 1. Study sites along the eastern Ligurian Riviera, Italy. Major rivers also shown are the major hydrodynamic forces. Around $50 \%$ of the waves are derived from 210 to $225^{\circ}$, with the other sectors $\left(15^{\circ}\right)$ accounting equally for the remaining waves (The Medatlas Group 2004).

The start point of each transect was located in an unbiased, haphazard fashion and samples were collected at this point and every $10 \mathrm{~m}$ (measured with a tape measure), resulting in a sample size of 15 for each site. Each sampling point was also logged with a GPS (accuracy $<10$ m, RMS Garmin eTrex H). At each sampling point, we sampled turf infauna with a stainless steel corer $(5 \mathrm{~cm}$ internal diameter). The corer was pushed firmly into the turf and encrusting fauna; the top of the core was then plugged while a flexible metal blade was slid against the rock to free the encrusting turf and organisms contained within the corer. One core sample, collected for the analysis of infauna, was placed into a plastic jar, preserved with $70 \%$ isopropyl alcohol and stained with Rose Bengal. Another core sample was collected for the analysis of turf organic matter and sediment content. This core was stored in a plastic bag, kept cool and in the dark until frozen on return to the laboratory. At each sampling point, we also visually censused a $20 \times 20 \mathrm{~cm}$ quadrat to identify the large organisms that define the algal turf habitat and assess quadrat species density (number of species per quadrat). To provide percent cover estimates, the quadrat was divided into 25 equal squares, each representing $4 \%$ of coverage. Each taxon observed was given an abundance rank (1 to 4$)$ within each square $(1 / 4$ of the square $=1 \%)$ and the total percent substrate cover was obtained by adding up scores for all squares where the taxon was present. Organisms filling less that $1 / 4$ of a square $(<1 \%)$ were given a percent cover value of 0.5 (following Dethier et al. 1993). Visible, solitary organisms were also counted in each quadrat. The same 2 researchers performed density and percent cover estimates from visual quadrats at each site; preliminary data analysis revealed no bias between observers. At each sampling point, turf height, and distance below the bottom of the barnacle zone (predominantly Chthamalus stellatus) were measured; we used the latter variable to indicate if our sampling points varied significantly in wave exposure relative to the biological zonation. For each point, we also estimated rock slope by eye. Within the length of the transect at each site, we made 5 measurements of the sinuosity of the shoreline. A chain (oval links of internal diameter $1.4 \times 6 \mathrm{~mm}$; chain length $11.4 \mathrm{~m}$ ) was carefully laid along the coast following minor indentations at the same tidal height as we conducted the sampling. The straight-line distance along the coast covered by the chain was then measured to calculate the sinuosity of the shore (hereafter called Sinuosity [chain]). 
Preserved macrofauna were extracted by carefully teasing the turf apart over a $0.5 \mathrm{~mm}$ mesh sieve while rinsing with tap water. Macrofauna were then identified to the lowest practical level of taxonomic resolution and enumerated.

Estimation of local-scale variables. Samples for turf total organic and sediment content were defrosted and air dried. Then algae and large organisms with calcified shells (e.g. mussels and barnacles) were removed from the sample. Samples were then dried at $60^{\circ} \mathrm{C}$ for $48 \mathrm{~h}$, weighed, then combusted at $400^{\circ} \mathrm{C}$ for $6 \mathrm{~h}$, and re-weighed to measure total organic and inorganic sediment content respectively.

Habitat structure is generally defined as variation in the relative abundance of different habitat elements (habitat heterogeneity) and the absolute abundance of individual habitat elements (habitat complexity) (McCoy \& Bell 1991). On the algal turf dominated shore, the large, easily visible and usually quantified organisms provide much of the habitat structure for associated infauna. We used visual quadrat surveys to define aspects of both the complexity and heterogeneity of the infaunal turf habitat. From these, we calculated species density per quadrat, $\beta$-diversity (Lande 1996), and the multivariate index of dispersion (IMVD) based on Bray-Curtis similarities (Warwick \& Clarke 1993) for each site. We also constructed a habitat complexity index based on the percent cover of macroalgae (AHCI). To calculate the AHCI for each quadrat, the morphology of individual species was allocated to 1 of 5 groups. These ranged from coralline paints and algal films (score 1) to filamentous turf (score 2), coralline turf (score 4), small bushy algae (score 7) and large 'canopy' formers (score 10; note the largest algae on these shores are only $\sim 20 \mathrm{~cm}$ tall). The scores of the 5 groups were multiplied by their percent cover and summed up for each quadrat sample.

Estimation of broad-scale variables. GPS locations of each site were plotted on 1:5000 map of the Ligurian coastline in ARCGIS (v9.2). From this, we calculated the aspect of each site relative to the main wave direction $\left(225^{\circ}\right)$ and the distance from each site to each of the major rivers (Bisagno, Recco, Rapallo, Entella and Magra). Two different measures of fractal dimension were taken from ARCGIS, in order to have measurements of habitat rugosity at a larger scale than the Sinuosity (chain), encompassing the whole site extent $(150 \mathrm{~m})$. Fractal (GIS) was defined as: $D=\log (\mathrm{n}) /$ $[\log (\mathrm{n})+\log (d / L)]$, where $\mathrm{n}$ is the total number of line segments, $d$ is the distance between the start and end points of the line, and $L$ is the cumulative length of all line segments, where $d$ was set at the highest level of resolution on the 1:5000 map of the Ligurian coastline. Sinuosity (GIS) was defined as: $S=L / L_{\text {sf }}$ where $L$ is the cumulative length of all line segments, and $L_{\mathrm{sf}}$ is the distance between the start and end points of the transect. Sinuosity (GIS) is calculated in the same way as our Sinuosity (chain) measurements.

Statistical analyses. To assess if our sample size was sufficient to characterise infaunal species richness, we calculated species accumulation curves using EstimateS (Colwell 2009). Sampling theory dictates that increases in abundance should lead to increases in species richness (Connor \& McCoy 1979), possibly confounding diversity comparisons. To assess the magnitude of this potential problem, we plotted species accumulation curves based on both number of individuals and number of samples, and we also plotted Coleman rarefaction curves within and across sites (see Gotelli \& Colwell 2001, Colwell 2009). We also developed a scatter plot of the number of individuals and number of species per core to provide insight into abundancerichness correlations within and across sites.

Spatial structure in species density and abundance within sites was estimated using Moran's spatial autocorrelation coefficient (I) (Rangel et al. 2006). Values of $I$ were calculated for 7 distance classes that maximized the balance in the number of sample pairs per class (i.e. those samples lying $10 \mathrm{~m}$ apart: 10-25, 25-35, $35-50,50-65,65-85,85-120 \mathrm{~m}$ of each other). The null hypothesis of $I=0$ for each distance class was tested using 1000 permutations. Significant coefficients indicate that a distributional pattern exists and allow estimates of the scales at which average patch structures occur. Autocorrelograms were interpreted to identify various forms of mean spatial pattern using the guidelines presented by Sokal \& Oden (1978) and Legendre \& Fortin (1989). Before interpreting the correlogram, a 'global' test was performed to check whether the correlogram contained at least one value that was significant at $\alpha=\alpha / v$ level, where $v$ is the number of tests performed (Oden 1984).

Two simple initial multivariate analyses were undertaken to characterise variation in the infaunal turf community within and across sites: (1) Within site similarities were calculated based on Bray-Curtis similarities (Clarke \& Gorley 2006). (2) Correspondence analysis (CA) was used to display differences in infaunal community composition within and between sites, with indirect gradient analysis then used to calculate and display relationships to our explanatory variables (ter Braak 1986).

Canonical Correspondence analysis (CCA) was then used, in conjunction with variance partitioning procedures (Borcard et al. 1992, 2004, Borcard \& Legendre 1994, Anderson \& Gribble 1998), to determine the relative size of variability (inertia) associated with localscale habitat features, broad-scale environmental drivers, the information explained jointly by these 2 factors, purely spatial factors (defined by latitude and 
longitude), and unexplained variability. In this context, the purely spatial factors represent a surrogate for dispersal variables and unmeasured environmental variables that change along the coast. Only a simple expression of latitude and longitude were used, as opposed to developing more complicated polynomial surfaces; as with the available number of sites, we restricted our interest to gradual change along the coast. We also did not determine what proportion of the local or broad-scale environmental variables was spatially structured, as this was not the focus of our investigation. Local scale variables were turf height, sediment, and organic content, distance to barnacles, slope, AHCI, quadrat species density, IMVD, $\beta$-diversity, and Sinuosity (chain). Broad scale environmental variables were wave exposure, Fractal (GIS), Sinuosity (GIS), and distance to major rivers. Analyses were performed using CANOCO (ter Braak 1987) on raw abundances, and log and square root transformed data. Only the partitioning based on raw abundance data is presented, as results were not transformation specific.

We then investigated how feeding and mobility of different turf infauna were affected by the variables listed above. Traits related to feeding and potential adult and larval mobility for the identified species/genera/families were derived from the relevant taxonomic literature, life history reviews (e.g. Giangrande 1997), the useful trait database (www.marlin.ac.uk/biotic/; last cited 10 November 2009), as well as our observations of species morphology. For analyses associated with feeding traits, the species abundance matrix was coded into 5 feeding groups (suspension feeders, deposit feeders, grazers, predator/scavengers and parasites) using weighted coding where the feeding strategy of each species summed to 1 (Chevenet et al. 1994). For example, an obligate suspension feeding species would score 1 (in the suspension feeder class), whereas a species with a more flexible feeding strategy might be scored as deposit feeder 0.2, grazer 0.2 and predator/scavenger 0.6. Similarly, the species abundance matrix was coded for adult and larval mobility. Adult mobility categories were sedentary, tube builder, mobile within turf, active local swimming and drifting/rafting. Larval mobility categories were substrate attached, brooded, and planktonic. For example, a barnacle was expected to be capable of wide larval dispersal and low adult dispersal. In contrast, an adult syllid polychaete could be capable of moving in the turf and swimming in the water column, although its larvae are brooded. The percentage of individuals at each site allocated to the different feeding traits or mobility modes are presented in Appendix 1.

The mobility and feeding traits datasets were subjected to the same type of multivariate analyses as the original dataset. Multivariate variance portioning was also conducted on subsets of the original dataset containing taxa defined by feeding (suspension feeders, predators, grazers or deposit-feeders) or mobility traits (highly mobile as adults and larvae, highly mobile as larvae but not as adults, or not highly mobile as adults or larvae). For these analyses, the results were rescaled to represent a percentage of the explained variability to allow more direct comparisons of the relative importance of broad scale versus local variables.

Finally, regression models were developed for the univariate measures using the same mix of local, spatial and broad-scale variables. These were initially conducted at the individual core level; however, only low amounts of variability were explained by this method $(<20 \%)$. Site means and 90th percentiles of the local habitat variables were then calculated and used as the explanatory variables, while the dependent variables were site means of species density, infaunal abundance, and abundance of each of the feeding types and dispersal categories. The appropriate error structure for Generalized Linear Models (GzLM; McCullagh \& Nelder 1989) were determined using visual inspection of half-normal plots of residuals and plots of residuals versus predicted values. Backwards elimination and an exit value of $p=0.15$ was used to produce the most parsimonious model (Crawley 1993). Colinearity diagnostics were examined (see Belsley et al. 1980) for all GzLM analyses to ensure that highly correlated environmental variables were not included in the final model. If over dispersion was indicated for Poisson error structures (Pearson $\chi^{2} / \mathrm{df}>2$ ), quasi-likelihood estimation was used.

\section{RESULTS}

\section{Habitat variation within and between sites}

Fractal (GIS) dimension was similar across sites and close to 1 , indicating a linear coastline at the 1:5000 map scale (Appendix 1). However, within sites, Sinuosity (chain) measurements showed the coastline to be more convoluted, with slightly stronger variability between sites. Sites varied strongly in exposure to the predominant wave direction, and the within-site habitat characteristics of rock slope and turf height also showed variation both within and between sites (Appendix 1). In contrast, the height to barnacles, turf sediment and organic content were less variable. The range of these local and broad-scale habitat variables defines the environmental scope of our study.

Macroalgal communities are dominant along Ligurian rocky shore. In particular, canopy-forming species (e.g. Cystoseira spp.) and coralline turf represent 
the most frequent assemblages along natural rocky shores. The algal turf we sampled was composed of a complex matrix of small Corallinales (e.g. Corallina spp, Jania spp.), Ceramiales (e.g. Laurencia complex, Chondria spp.) and other filamentous algae (e.g. Cladophorales, Sphacelariales).

\section{Estimating species richness}

The rate of infaunal turf species accumulation was similar across all sites and slowed markedly after the collection of 8 cores. Despite this, none of the species accumulation curves reached an asymptote at $n=15$ (data not presented), which is common for marine biodiversity studies (Gray 2002). Sample and individualbased species accumulation and Coleman rarefaction curves were very similar: species were initially accumulated marginally faster in curves normalised by number of individuals rather than samples, but both curves converged well before actual site- and totalspecies richness was achieved. Across all sites, 58 infaunal turf dwelling taxa were collected with site species richness ranging from 38 at Framura to 31 at Punta Chiappa-east. While, across all sites, there is a

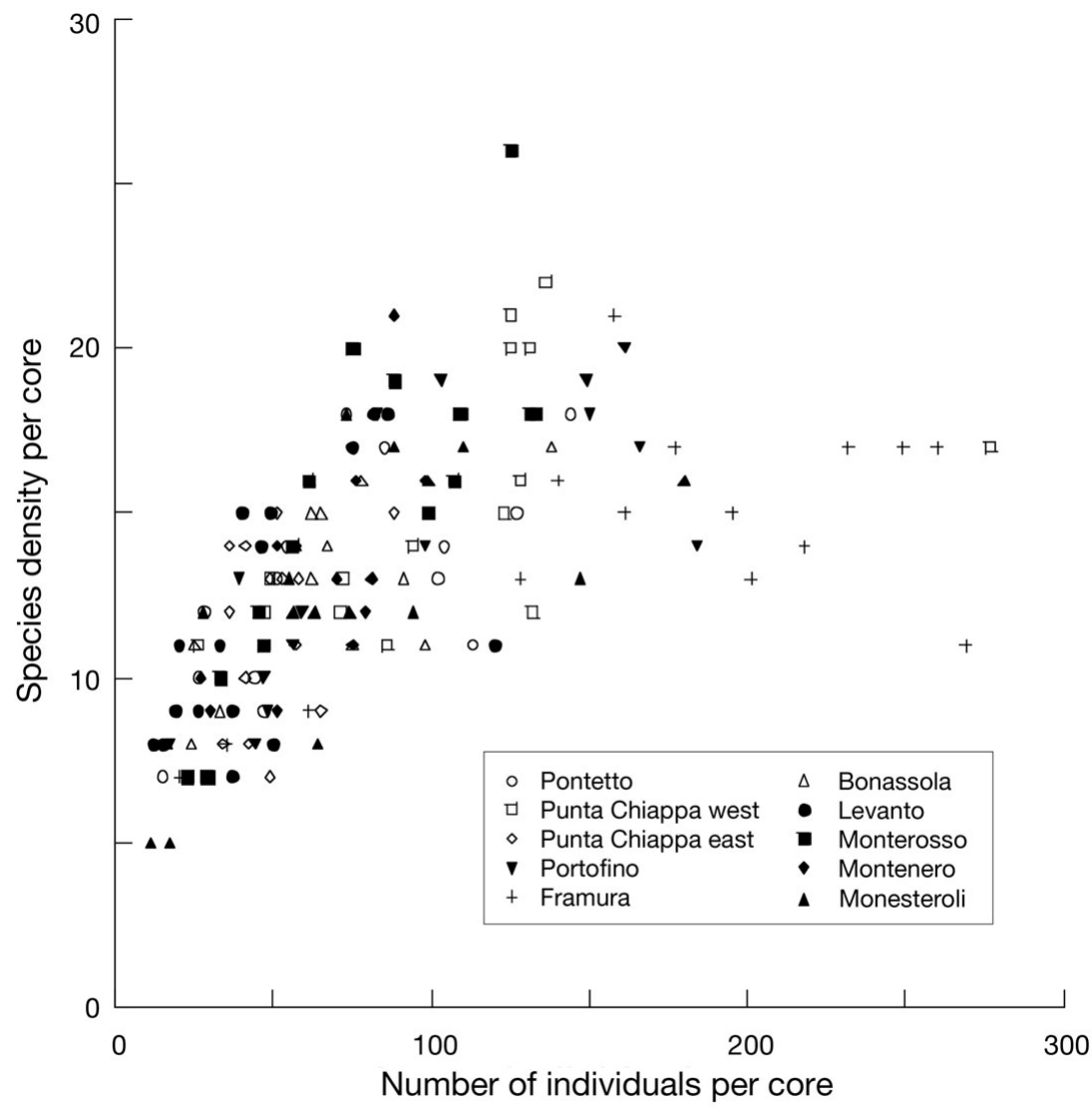

Fig. 2. Species density $\times$ abundance for all 10 sites significant relationship between infauna abundance and species density ( $\mathrm{p}<0.0001, \mathrm{n}=150$ ), variability was high with some strong site-dependent effects (Fig. 2). These results, together with the high degree of overlap between sites in range and slope, indicate that our sample-based comparisons of richness relative to turf habitat were not biased by variations in abundance between sites.

\section{Pattern matching between turf habitat features and infaunal communities}

Analysis of the similarity of turf infaunal community composition across sites showed that individual sites only differed by a maximum of $\sim 12 \%$ (Bray-Curtis similarity). Framura was the most dissimilar site, followed by Punta Chiappa-west, and the clustering of sites did not match their geographic relationships (Fig. 3). In contrast, there was greater variability within and between sites in the 3 turf habitat characteristics measured at the core scale (turf height, quadrat species density and AHCI; Fig. 4) and in the infaunal turf species density and abundance across sites (Fig. 5). Turf height varied between samples by $\sim 28 \mathrm{~mm}$ and exhibited the highest median and range at Framura. Portofino exhibited the lowest median turf height but a wide range. Median quadrat species densities varied from $\sim 8$ to 12 quadrat $^{-1}$. Highest median and range species densities were recorded at Monterosso, with large ranges also apparent at Punta Chiappa-east and Monesteroli (Fig. 5). The AHCI recorded lowest values at Framura (Fig. 4). Interestingly, the site variation in the AHCI index showed little positive relation to turf height or species density. The abundance and variability of infaunal turf organisms was highest at Framura (Fig. 4). The most consistent abundance values were recorded from Punta Chiappa east, which did not exhibit the lowest median density. Median core species density varied between 13 and 17 , with highest variation at Monterosso and lowest at Bonossola.

Spatial patterns in the distribution of infaunal turf communities were apparent in the autocorrelation structure of species density and abundance (Table 1). Only one variable (species density at Pontetto) demonstrated sig- 


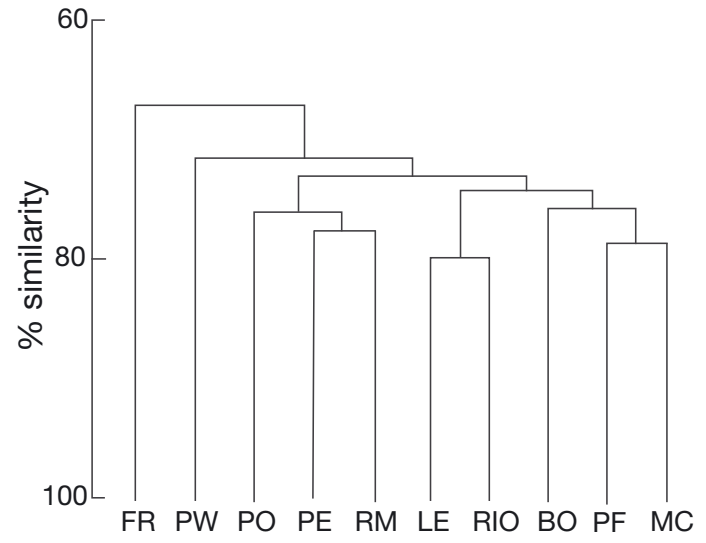

Fig. 3. Bray-Curtis similarity in turf infaunal composition between sites. FR = Framura; $\mathrm{PW}=$ Punta Chiappa west; $\mathrm{PO}=$ Pontetto; $\mathrm{PE}=$ Punta Chiappa east $; \mathrm{RM}=$ Montenero; $\mathrm{LE}=$ Levanto; RIO $=$ Monesteroli $; \mathrm{BO}=$ Bonassola $; \mathrm{PF}=$ Portofino; $\mathrm{MC}=$ Monterosso

nificant negative autocorrelation at the smallest distance $(10 \mathrm{~m})$, implying that spatial variability at scales smaller than $\sim 10 \mathrm{~m}$ is not an important phenomenon for these infaunal turf communities. Rather, patches on the 10 to $65 \mathrm{~m}$ scale were apparent. There was no evidence of similar scales of patchiness in species density and abundance occurring at any site.

\section{Multivariate relationships between turf infaunal communities and habitat features}

Ordination of infaunal community composition did not suggest strong environmental forcing (Fig. 6A). The first axis of the CA explained $16 \%$ of the variability and was correlated with geographic variables (latitude, longitude and distance from Magra River), wave exposure, Sinuosity (chain) and distance to barnacles. The second axis explained a further $12 \%$ of the variability in community composition and was correlated with turf height, IMVD, AHCI and $\beta$-diversity. Along these 2 axes, the ordination shows that individual core samples from all sites are inter-mingled. Framura and Pontetto exhibited both high variability in community composition within cores and strong variation along axis one. As indicated by the length of the line associated with each factor, local and broad-scale factors had similar magnitude of effect.

CAs based on mobility or feeding traits (Fig. 6B,C) showed that samples were less dispersed than in the species CA. These CAs explained 30.5 and $69.1 \%$ (axis 1) and 18 and $20 \%$ (axis 2) of the variance for dispersal and feeding traits respectively. Similar to the species CA, the dispersal trait axis 1 was correlated
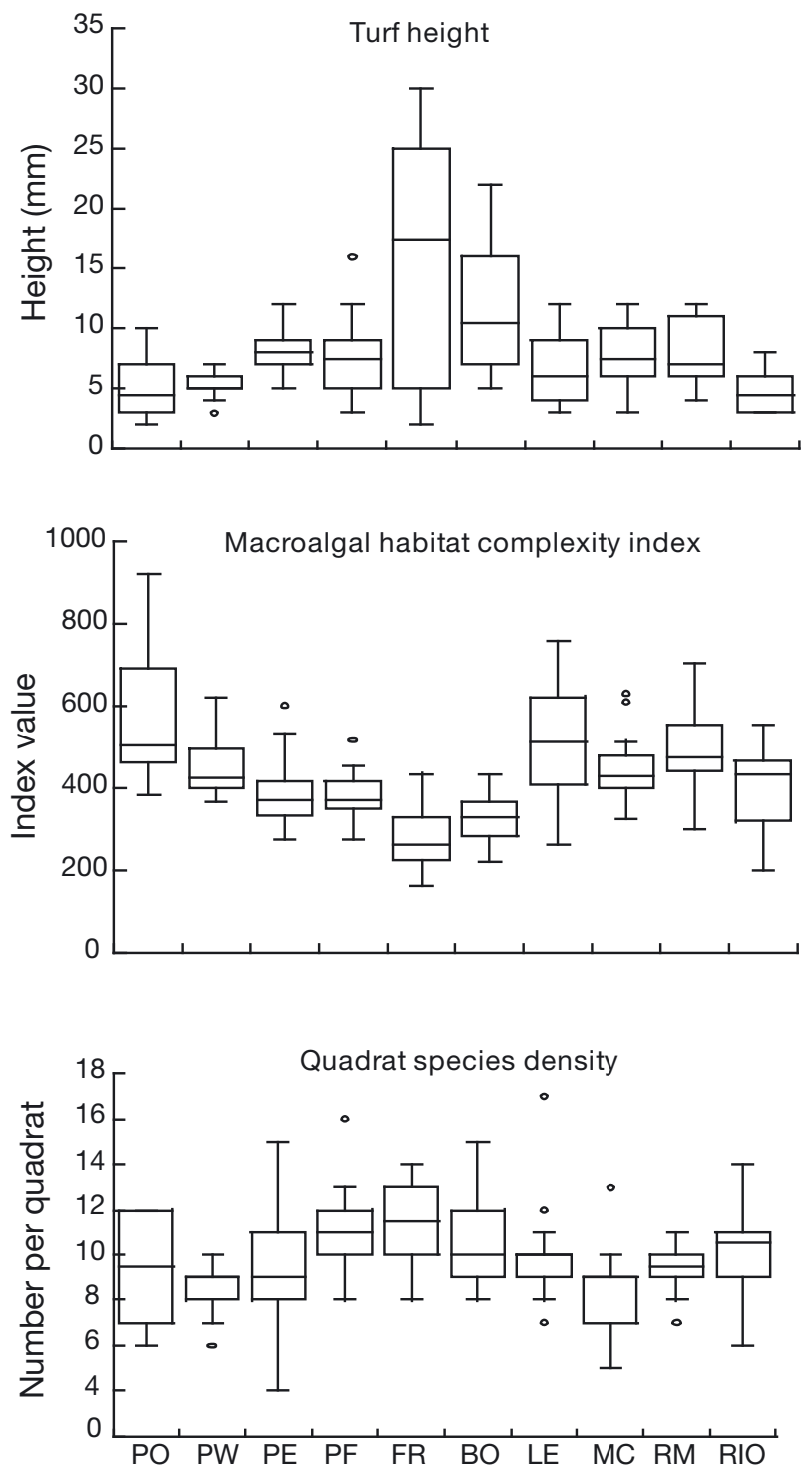

Fig. 4. Distribution in local habitat variables measured at each sampling point across each site. Box plots: non-parametric representing median, interquartile range, maximum and minimum. Site key see Fig. 3

with latitude, longitude and Fractal (GIS). Exposure and turf habitat features (AHCI, IMVD, species density, $\beta$-diversity and turf height) were still important influences but did not correlate as strongly with axis 2 as in the species CA. This compression along axis 1 of the ordination was further accentuated in the feeding trait CA, with a less well-defined split between broadscale, spatial and local turf-habitat associated variables. In this CA, the geographic variables (longitude and latitude) still correlated well with axis 1, as did exposure, Fractal (GIS) and IMVD. Only turf sediment content was correlated with axis 2 . 
The partitioning of variation in the CCAs between purely spatial, broadscale, local-scale and the broad*local intersection showed that all these sources contributed to variation (Fig. 7). Unexplained variation was high, although this decreased when instead of using taxa, we used feeding or dispersal traits. High amounts of unexplained variation are frequently found in multivariate community analyses and are not held to minimise the importance of the variability that can be explained (ter Braak 1986). The amount of variability explained by broad or local-scale variables were similar to that explained purely by spatial variation and was generally low, despite the nature and number of factors included. However, the cross-scale intersections between local and broad-scale habitat variables were consistently more important than the pure effects at either scale. Some differences in the partitioning of different sources of variation were related to dispersal mode. Species that had the poten-

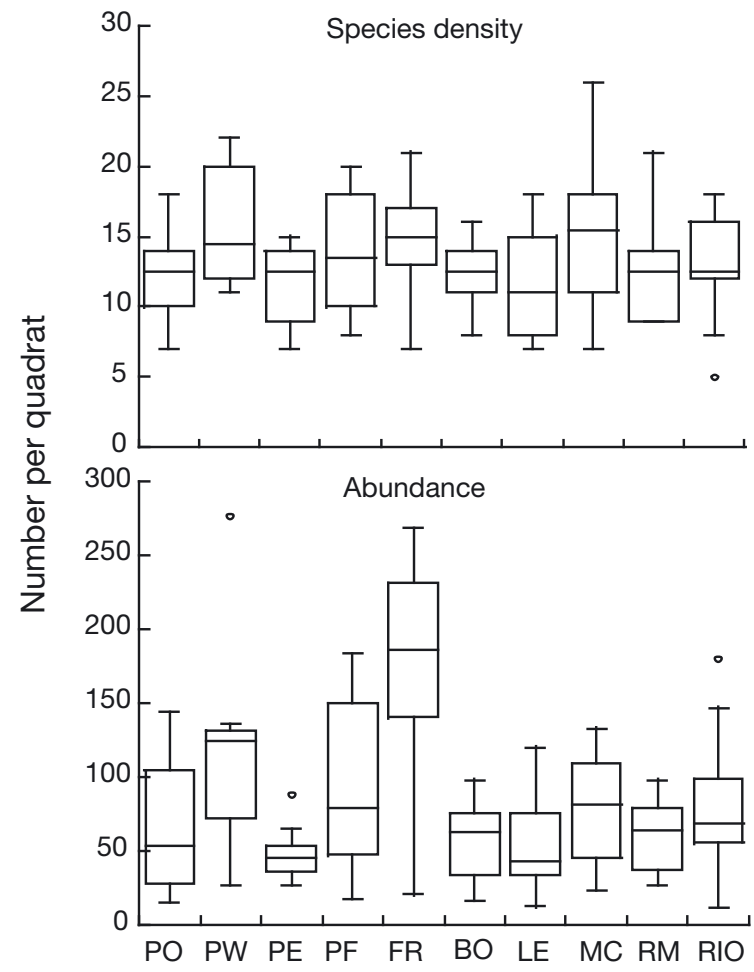

Fig. 5. Distribution in turf infaunal species density and total abundance across each site. Box plots: non-parametric representing median, interquartile range, maximum and minimum. Site key see Fig. 3 tial to disperse widely, as both adults and larvae were more affected by broad-scale factors. While this was the least important factor for species with traits of low adult and juvenile mobility, local-scale habitat features were more important. For feeding groups, differences in variance partitioning were also apparent. Deposit feeders and grazers showed similar results, while predators appeared to be the most sensitive to local habitat variability.

\section{Modelling the role of habitat features in species density and abundance of turf infaunal communities}

Apart from infaunal species density and abundance (Table 2), we were only able to develop regression models that explained $>20 \%$ of the variability for 1 feeding group (suspension feeders) and 1 mobility group (low adult and high larval dispersers) (Table 2). Similar to the multivariate analyses of the community composition, all the models in Table 2 emphasise the importance of elements of turf habitat structure, in combination with broader-scale habitat features. Different factors were important in influencing infaunal turf species density and abundance. Interestingly, the density of suspension feeders in the turf was strongly influenced by the density of small mussels (authors' unpubl. data), which also made an important contribution to the low adult, high larval dispersers; yet, except for the turf habitat structure features (IMVD and turf height), different factors or the same factor working in opposite directions contributed to the GzLMs. This indicates that the feeding and mobility trait groupings were not strongly affected by the same species. 


\section{DISCUSSION}

Leaving aside the obvious reality that turf provides a habitat for infauna that cannot exist on bare rock, our analysis of patterns within and between sites revealed only weak relationships between infaunal turf commu-

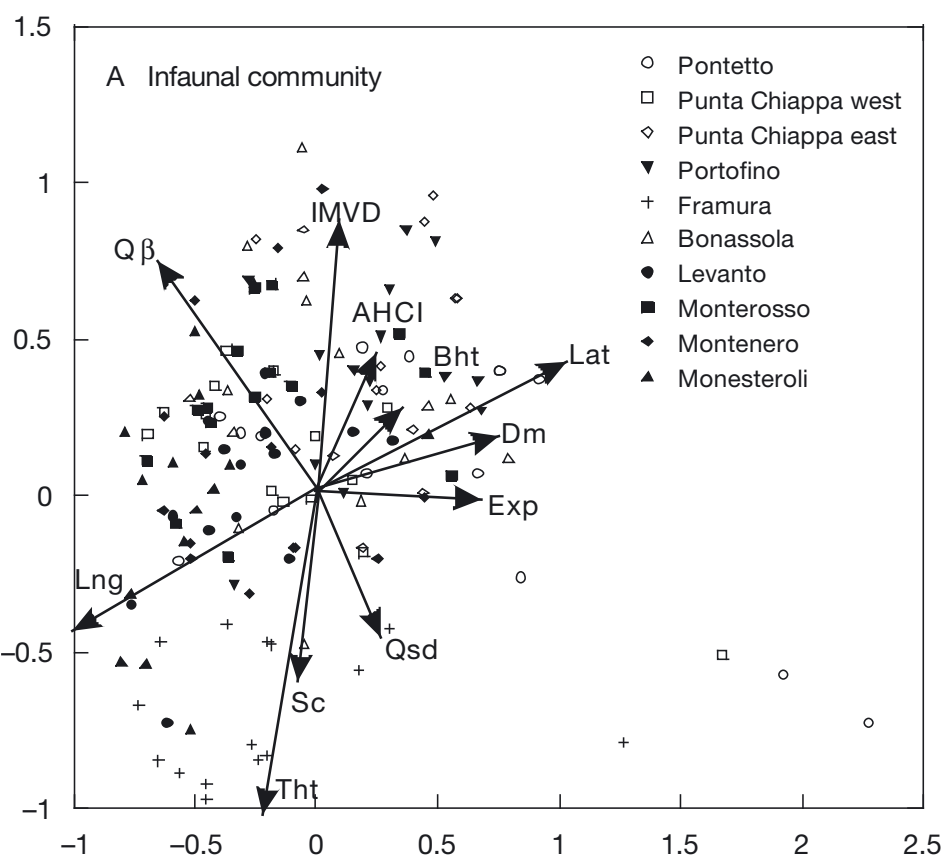

nities and the structure and complexity provided by the algal turf habitat. This is a surprising result as, for the larger animals living on rocky shores, habitat complexity created by large macroalgae has long been recognised as an important influence on populations (Dean \& Connell 1987), ameliorating physical stresses (waves, light and temperature) and providing refugia from predation. We also found similar magnitudes of variation in community structure within and between sites with no strong environmental drivers. The spatial structure of infaunal species density and abundance was patchy on the 10 to $100 \mathrm{~m}$ scale, and did not indicate a very strong role for smaller scale heterogeneity $(\sim 10 \mathrm{~m})$ in infaunal turf communities of the intertidal zone of eastern Liguria. Finally, the species richness contributed by turf dwelling infauna was greater than that recorded by visual sampling, irrespective of the differences in the sample area. This implies that ignoring the infauna drops estimates of richness by $>50 \%$ for macrofaunal organisms (i.e. $>0.5 \mathrm{~mm}$ ) on these rocky shores.

One potentially important problem confounding the identification of diversity-habitat relationships is that patterns in richness can be driven by abundance. That is, the turf height-infaunal abundance relationships we observed could drive richness simply because increasing the number of individuals in a sample increases the chance of finding more species (Gotelli \& Colwell 2001). This potential sampling artefact does
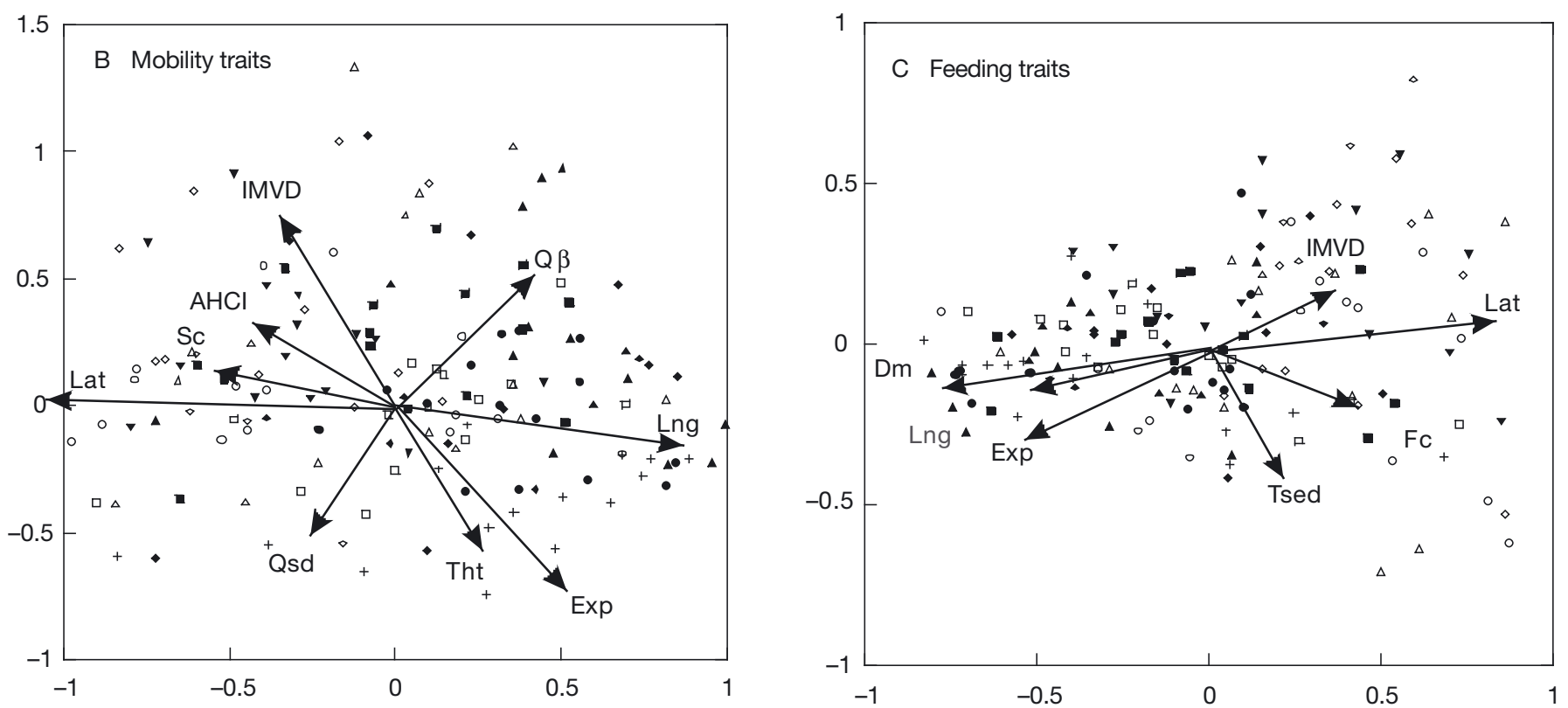

Fig. 6. Canonical correspondence analysis of (A) infaunal turf community, (B) mobility and (C) feeding traits, showing relationships with significant spatial, local and broad-scale environmental variables. Environmental axes are scaled up $3 \times$ for clarity. Qsd = Quadrat species density; FC = Sinuosity (chain); Tht $=$ Turf height; Lng = Longitude; $Q \beta=$ Quadrat $\beta$-diversity; IMVD = Quadrat index of multivariate dispersion; Tsed $=$ Turf sediment content; $\mathrm{AHCI}=$ Macroalgal habitat complexity index; $\mathrm{Bht}=$ Height to barnacles; Lat $=$ Latitude $;$ Dm = Distance to River Magra; Exp = Wave exposure 

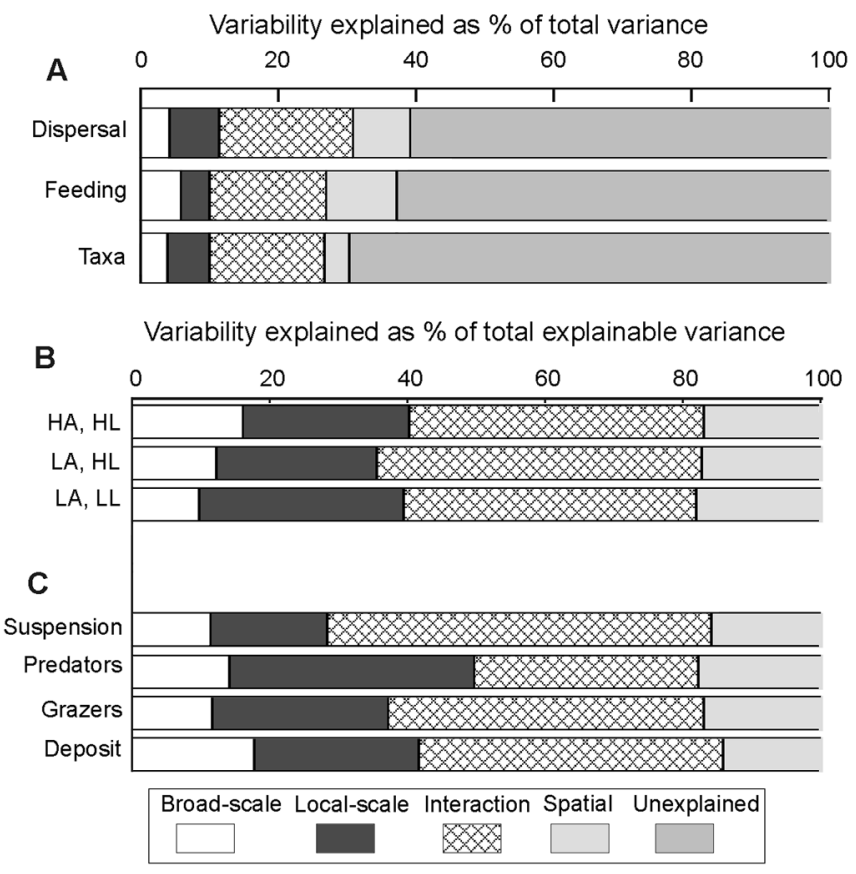

Fig. 7. Multivariate partitioning of variability in canonical correspondence analyses associated with broad-scale, localscale, purely spatial processes, and the broad*local intersections. (A) Infaunal turf community (taxa), dispersal and feeding traits. (B) Specific dispersal traits $(\mathrm{H}=$ high mobility; $\mathrm{L}=$ Low mobility; $\mathrm{A}=$ Adult; $\mathrm{L}=$ Larvae). (C) Specific feeding traits

not refute the importance of habitat structure in influencing diversity, but it does imply that the mechanisms that underpin such relationships may be indirect rather than directly related to increased resources and niche space in complex habitats. Highly productive areas tend to support more individuals (Wright 1983, Srivastava \& Lawton 1998), although such relationships are not necessarily linear (Michalet et al. 2006). The lack of consistent linear relationships between infaunal abundance and species density within sites, combined with our analysis of sample- and individual-based species accumulation curves and species density-abundance relationships, do not support consistent abundancerichness relationships across sites. This type of abundance-richness confounding may not be important in many marine systems because the quality and quantity of resources are dynamic and there are multiple scales of heterogeneity in diversity and abundance relationships.

The high degree of unexplained variability in both our multivariate and univariate models could reflect a failure in our study design, e.g. lack of appropriate measures of environmental drivers, small spatial coverage or sampling when habitat-diversity relationships were weak (Benedetti-Cecchi 2001). However, we measured a broad range of variables representing local biogenic habitat structure, rock slope, fractal dimension, wave exposure, proximity to rivers (as sources of freshwater, nutrients and sediment), as well as geographic location. We included 3 surface complexity factors measured at 2 scales of resolution (i.e. Sinuosity [chain], Fractal [GIS] and Sinuosity [GIS]) that could confound comparisons between sites (Johnson et al. 2003, Kostylev et al. 2005). Our spatial scales of variability ranged from $10 \mathrm{~s}$ of $\mathrm{m}$ within sites to $10 \mathrm{~s}$ of $\mathrm{km}$ between sites, and our study encompassed a total extent of $80 \mathrm{~km}$. Our snapshot sampling in summer was a time of high macroalgal development (Ballesteros 1991) and high infaunal abundance following spring-early summer recruitment (Giangrande et al. 2002). Physical gradients associated with light, temperature and desiccation are expected to be strong during summer, potentially resulting in strong amelioration of these stressors by the algal turf habitat. Our sampling was conducted outside the stormiest time of year (winter). Storms can disturb the turf habitat and potentially resuspend and transport infauna. These features should increase our potential for identifying strong patterns in community-habitat relationships.

Although the relationships between infaunal turf communities and the structure and complexity provided by the algal turf habitat were weak, we did

Table 2. Regression models explaining $>20 \%$ of the variability in species density, total abundance or abundance of various biological traits explained by spatial, local and broad scale habitat variables

\begin{tabular}{|c|c|c|c|}
\hline & $\mathrm{R}^{2}$ & $\mathrm{p}$ & Explanatory variables \\
\hline Suspension feeders & 48 & $<0.0001$ & $\begin{array}{l}\text { + Exposure - Distance to Magra + Sinuosity (chain) + Turf height - } \\
\text { IMVD }\end{array}$ \\
\hline Low adult \& high larval dispersers & 55 & $<0.0001$ & $\begin{array}{l}\text { - Latitude }+ \text { Longitude }+ \text { Exposure }+ \text { Distance to Magra }+ \text { Turf height }- \\
\text { Quadrat species density - IMVD }\end{array}$ \\
\hline Species density & 88 & 0.0134 & $\begin{array}{l}\text { + Slope - Longitude }+90 \text { thpercentile of Turf height }- \text { Quadrat species } \\
\text { density }\end{array}$ \\
\hline Infaunal abundance & 83 & 0.0379 & + Exposure + Slope - AHCI - Longitude \\
\hline
\end{tabular}


detect them. Turf height and a variety of measures of habitat complexity derived from the visual quadrats (species density, $\beta$-diversity, AHCI and IMVD) did influence the infaunal community composition. Similarly, a lack of strong and consistent patterns of association between infaunal polychaetes and the canopyforming small macroalgae (Cystoseira amentacea) has been noted across tens of centimeters to hundreds of kilometers scales in the shallow subtidal of southern Italy (Fraschetti et al. 2002). In the same region, only small, albeit significant, differences in infaunal polychaete assemblage have been observed between sites (Giangrande et al. 2003). However, on the Mediterranean coast of Spain, the dominant turf forming species and height of the turf assemblage strongly influenced the associated polychaete assemblage (Tena et al. 2000). Similarly, on the Atlantic coast of Spain, high structural complexity of the turf habitat increased the associated polychaete diversity (Serrano \& Preciado 2007).

Differences in sampling design, analytical procedures and geography make it difficult to generalise across studies. In particular, it is often problematic to assess how much variability in infaunal community composition is explained by factors operating over different spatial scales. Kelaher et al. (2001) identified spatial variation on the 50 to $70 \mathrm{~m}$ scale as more important than broad-scale variation between southeast Australian shores for coralline turf dwelling infauna. Lack of consistent pattern across shores led these authors to conclude that, within the extent of their study $(120 \mathrm{~km})$, only local processes were important. Subsequent small-scale transplant experiments, however, emphasised that the specific properties of turf algae were not as important an influence on infauna as tidal elevation (Kelaher et al. 2003). Along the coast of Patagonia, Argentina, variability in the molluscan infauna of coralline turf was high at small scales and associated with coralline algal frond density and length. Nevertheless, variability was also high at large scales, associated with regional environmental factors (Kelaher et al. 2007). Similarly, a recent study from Brazil emphasised both site and regional scale variability affected composition and species turnover of turf dwelling infauna (Liuzzi \& Gappa 2008). Different scales of variability can be important for different ecological variables (Archambault \& Bourget 1996). Our results emphasise the importance of both within-site turf habitat complexity and between-site environmental and spatial factors. Our partitioning of multivariate variance showed the strongest role for information that could not be simply decomposed into either local or regional scales. Such cross-scale relationships have important consequences for emergent spatial relationships, temporal dynamics and ecological function
(Guichard \& Bourget 1998, Guichard \& Steenweg 2008, Hewitt \& Thrush 2009), and highlight the benefit of multiscale analysis over strict hierarchal designs (Hewitt et al. 2007).

The analysis of biological traits associated with feeding and mobility provided insight into why the habitat and environmental factors we measured had a weak influence on the structure of infaunal turf communities. Feeding groups, other than suspension feeders, were dominated by species capable of switching strategies between autotrophic and detrital based foodwebs. Habitat descriptions from the taxonomic guides used to identify our infaunal species typically reported wide habitat preferences for many species, emphasising wide niches, which our results supported (see also Herman et al. [1999] for soft-sediment habitats). This suggests little spatial structure associated with food resources. Analyses based on dispersal strategies suggested that species with different strategies relate to habitat features on different scales. Fraschetti et al. (2006), studying the role of dispersal mode for hydroids on habitat forming algae, also found weak relationships due to inconsistent patterns of variability with spatial scale. A lack of strong relationship between local habitat characteristics and community structure could imply a dominance of mobile species that are able to move rapidly between variable resource patches. Such mobility strategies provide a rapid response to local physical disturbance for infaunal turf communities (Huff \& Jarett 2007). Broadening the scope of community descriptions for rocky shores to include infaunal turf dwelling species increases the range of dispersal strategies represented on the shoreline from the traditional emphasis on large, relatively sedentary organisms. Including adult life stages that are likely to be mobile on the 10 to $100 \mathrm{~m}$ scale, associated with movement through turf and swimming and passive dispersal, should provide a clearer insight into disturbance-recovery processes operating over different spatial scales.

Infaunal turf communities and many habitat features were remarkably consistent along the Ligurian coast, making it difficult to assess niche size or define its dimensions from surveys. Yet surveys are commonly used to attribute environmental factors (spatially structured or not) to niche processes, with residual spatial variation being attributed to other processes, e.g. dispersal (Laliberte et al. 2009). Our results emphasise weak environmental filters on dispersal and growth, with wide niches for infaunal turf species and little amelioration of physical stresses by turf structure. In contrast with the relationships usually reported for larger and more sedentary rocky shore organisms, our results suggest variation in habitat structure does not influence infaunal communities; for the infauna, we 
infer this to imply little competition or habitat facilitation and a focus on dispersal, chance and a dynamic environment. This does not necessarily imply a lack of process at the scales encompassed by our sampling, as recent modelling predicts poor correlations between recruitment and density when community interactions drive pattern formation (Guichard \& Steenweg 2008). While the importance of such processes challenge our ability to interpret scale-dependent patterns, these features of the turf infaunal communities may have implications for recovery from disturbance, habitat loss and climate change effects on the shore.

Acknowledgements. We thank S. Vaselli, D. Pecorino, I. Sorbera, J. Serra, D. Caccia and V. Parravicini for help with various aspects of our field and laboratory work. A. Giangrande and L. Musco (University of Salento) and M.-C. Gambi (Stazione Zoologica Napoli) for their help with polychaete taxonomy. This research was supported by a Marie Curie International Incoming Fellowship to (FP7-PEOPLE-2007-42-IIF-ENV221065) to SFT. We thank the managers of the Portofino and Cinque Terre marine protected areas for permission to work in their reserves. This research complies with current Italian Law.

\section{LITERATURE CITED}

Abbiati M, Bianchi CN, Castelli A (1987) Polychaete vertical zonation along a littoral cliff in the Western Mediterranean. PSZNI: Mar Ecol 8:33-48

Abbiati M, Bianchi CN, Castelli A, Giangrande A, Lardicci C (1991) Distribution of polychaetes on hard substrates of the midlittoral-infralittoral transition zone, western Mediterranean. Ophelia 5:421-432

Anderson MJ, Gribble NA (1998) Partitioning the variation among spatial, temporal and environmental components in a multivariate data set. Aust J Ecol 23:158-167

Archambault P, Bourget E (1996) Scales of coastal heterogeneity and benthic intertidal species richness, diversity and abundance. Mar Ecol Prog Ser 136:111-121

> Asnaghi V, Chiantore M, Bertolotto R, Parravicini V and others (2009) Implementation of the European Water Framework Directive: natural variability associated to the CARLIT method on the rocky shores of the Ligurian Sea (Italy). PSZNI: Mar Ecol 30:505-513

Ballesteros E (1991) Structure and dynamics of North-western Mediterranean marine communities: a conceptual model. Oecol Aquat 10:223-242

Ballesteros E, Torras X, Pinedo S, Garcia M, Mangialajo L, de Torres M (2007) A new methodology based on littoral community cartography dominated by macroalgae for the implementation of the European Water Framework Directive. Mar Pollut Bull 55:172-180

Becker BJ, Levin LA, Fodrie FJ, McMillan PA (2007) Complex larval connectivity patterns among marine invertebrate populations. Proc Natl Acad Sci USA 104:3267-3272

Belsley DA, Kuh E, Welsch RE (1980) Regression diagnostics: identifying influential data and sources of collinearity. Wiley, New York, NY

Benedetti-Cecchi L (2001) Variability in abundance of algae and invertebrates at different spatial scales on rocky sea shores. Mar Ecol Prog Ser 215:79-92
Blanchard D, Bourget E (1999) Scales of coastal heterogeneity: influence on intertidal community structure. Mar Ecol Prog Ser 179:163-173

> Borcard D, Legendre P (1994) Environmental control and spatial structure in ecological communities: an example using oribatid mites (Acari, Oribatei). Environ Ecol Stat 1:37-61

> Borcard D, Legendre P, Drapeau P (1992) Partialling out the spatial component of ecological variation. Ecology 73: 1045-1055

Borcard D, Legendre P, Avois-Jacquet C, Tuomisto H (2004) Dissecting the spatial structure of ecological data at multiple scales. Ecology 85:1826-1832

Bulleri F, Benedetti-Cecchi L (2008) Facilitation of the introduced green alga Caulerpa racemosa by resident algal turfs: experimental evaluation of underlying mechanisms. Mar Ecol Prog Ser 364:77-86

Caley MJ, Carr MH, Hixon MA, Hughes TP, Jones GP, Menge BA (1996) Recruitment and the local dynamics of open marine populations. Annu Rev Ecol Syst 27: $477-500$

> Chevenet F, Dole'dec S, Chessel D (1994) A fuzzy coding approach for the analysis of long-term ecological data. Freshw Biol 31:295-309

Clarke KR, Gorley RN (2006) Primer v6: user manual/tutorial. Primer-E, Plymouth

Colwell RK (2009) EstimateS: statistical estimation of species richness and shared species from samples. Version 8.2. User's guide and application availbe at: http://purl.oclc. org/estimates

> Connor EF, McCoy ED (1979) The statisitcs and biology of the species-area relationship. Am Nat 113:791-833

> Coull B, Wells J (1983) Refuges from fish predation: experiments with phytal meiofauna from the New Zealand rocky intertidal. Ecology 64:1599-1609

Crawley MJ (1993) GLIM for ecologists. Blackwell, Oxford

> Dayton PK (1971) Competition, disturbance and community organisation: the provision and subsequent utilization of space in a rocky intertidal community. Ecol Monogr 41: 351-389

> Dean RL, Connell JH (1987) Marine invertebrates in an algal succession. III. Mechanisms linking habitat complexity with diversity. J Exp Mar Biol Ecol 109:249-273

> Dethier MN, Graham ES, Cohen S, Tear LM (1993) Visual versus random-point percent cover estimations: 'objective' is not always better. Mar Ecol Prog Ser 96:93-100

- Fraschetti S, Giangrande A, Terlizzi A, Miglietta MP, Della Tommasa L, Boero F (2002) Spatio-temporal variation of hydroids and polychaetes associated with Cystoseira amentacea (Fucales: Phaeophyceae). Mar Biol 140: 949-957

Fraschetti S, Terlizzi A, Bevilacqua S, Boero F (2006) The distribution of hydroids (Cnidaria, Hydrozoa) from micro- to macro-scale: spatial patterns on habitat-forming algae. J Exp Mar Biol Ecol 339:148-158

- Giangrande A (1988) Polychaete zonation and its relation to algal distribution down a vertical cliff in the western Mediterranean (Italy): a structural analysis. J Exp Mar Biol Ecol 120:263-276

Giangrande A (1997) Polychaete reproductive patterns, life cycles and life histories: an overview. Oceanogr Mar Biol Annu Rev 35:323-386

Giangrande A, Fraschetti S, Terlizzi A (2002) Local recruitment differences in Platynereis dumerilii (Polychaeta, Nereididae) and their consequences for population structure. Ital J Zool 69:133-139

Giangrande A, Delos AL, Fraschetti S, Musco L, Licciano M, Terlizzi A (2003) Polychaete assemblages along a 
rocky shore on the South Adriatic coast (Mediterranean Sea): patterns of spatial distribution. Mar Biol 143: 1109-1116

Gilg MR, Hilbish TJ (2003) The geography of marine larval dispersal: coupling genetics with fine-scale physical oceanography. Ecology 84:2989-2998

> Gili JM, Coma R (1998) Benthic suspension feeders: their paramount role in littoral marine food webs. Trends Ecol Evol 13:316-321

Gotelli NJ, Colwell RK (2001) Quantifing biodiversity: procedures and pitfalls in the measurement and comparison of species richness. Ecol Lett 4:379-391

Gray JS (2002) Species richness of marine soft sediments. Mar Ecol Prog Ser 244:285-297

Guichard F, Bourget E (1998) Topographic heterogeneity, hydrodynamics, and benthic community structure: a scale-dependent cascade. Mar Ecol Prog Ser 171:59-70

Guichard F, Steenweg R (2008) Intrinsic and extrinsic causes of spatial variability across scales in a metacommunity. J Theor Biol 250:113-124

Herman PMJ, Middelburg JJ, VandeKoppel J, Heip CHR (1999) Ecology of estuarine macrobenthos. Adv Ecol Res 29:195-231

Hewitt JE, Thrush SF (2009) Reconciling the influence of global climate phenomena on macrofaunal temporal dynamics at a variety of spatial scales. Glob Change Biol 15:1911-1929

> Hewitt JE, Thrush SF, Dayton PK, Bonsdorff E (2007) The effect of spatial and temporal heterogeneity on the design and analysis of empirical studies of scale-dependent systems. Am Nat 169:398-408

Huff TM, Jarett JK (2007) Sand addition alters the invertebrate community of intertidal coralline turf. Mar Ecol Prog Ser 345:75-82

Johnson M, Frost NJ, Mosley MWJ, Roberts MF, Hawkins SJ (2003) The area-independent effects of habitat complexity on biodiversity vary between regions. Ecol Lett 6:126-132

Kelaher BP, Chapman MG, Underwood AJ (2001) Spatial patterns of diverse macrofanual assemblages in coralline turf and their association with environmental variables. J Mar Biol Assoc UK 81:917-930

Kelaher BP, Underwood AJ, Chapman MG (2003) Experimental transplantations of corraline algal turf to demonstrate causes of differences in macrofauna at different tidal heights. J Exp Mar Biol Ecol 282:23-41

Kelaher BP, Castilla JC, Prado L, York P, Schwindt E, Bortolus A (2007) Spatial variation in molluscan assemblages from coralline turfs of Argentinean Patagonia. J Molluscan Stud 73:139-146

Kostylev VE, Erlandsson J, Ming MY, Williams GA (2005) The relative importance of habitat complexity and surface area in assessing biodiversity: fractal application on rocky shores. Ecol Complex 2:272-286

Laliberte E, Paquette A, Legendre P, Bouchard A (2009) Assessing the scale-specific importance of niches and other spatial processes on beta diversity: a case study from a temperate forest. Oecologia 159:377-388

Lande R (1996) Statistics and partitioning of species diversity, and similarity among multiple communities. Oikos 76 : $5-13$

> Legendre P, Fortin MJ (1989) Spatial pattern and ecological analysis. Vegetatio 80:107-138

> Levin LA, Talley TS (2002) Natural and manipulated sources of heterogeneity controlling early faunal development of a salt marsh. Ecol Appl 12:1785-1802

Liuzzi MG, Gappa JL (2008) Macrofaunal assemblages asso- ciated with coralline turf: species turnover and changes in structure at different spatial scales. Mar Ecol Prog Ser 363: $147-156$

Mangialajo L, Ruggieri N, Asnaghi V, Chiantore M, Povero P, Cattaneo-Vietti R (2007) Ecological status in the Ligurian Sea: the effect of coastline urbanisation and the importance of proper reference sites. Mar Pollut Bull 55:30-41

McCoy ED, Bell SS (1991) Habitat structure: the evolution and diversification of a complex topic. In: Bell SB, McCoy ED, Mushinsky HR (eds) Habitat structure, the physical arrangement of objects in space. Chapman \& Hall, London, p 3-17

McCullagh P, Nelder JA (1989) Generalised linear models, Chapman \& Hall, London

Menge BA, Sutherland JP (1987) Community regulation: variation in disturbance, competition, and predation in relation to environmental stress and recruitment. Am Nat 110: 351-369

Menge BA, Daley BA, Wheeler PA, Strub PT (1997) Rocky intertidal oceanography: an association between community structure and nearshore phytoplankton concentration. Limnol Oceanogr 42:57-66

> Michalet R, Brooker RW, Cavieres LA, Kikvidze Z and others (2006) Do biotic interactions shape both sides of the humped-back model of species richness in plant communities? Ecol Lett 9:767-773

> Norkko A, Hewitt JE, Thrush SF, Funnell GA (2006) Conditional outcomes of facilitation by a habitat-modifying subtidal bivalve. Ecology 87:226-234

> Oden NL (1984) Assessing the significance of a spatial correlogram. Geogr Anal 16:1-16

> Rangel TFLVB, Diniz-Filho JAF, Bini LM (2006) Towards and integrated computational tool for spatial analysis in macroecology and biogeography. Glob Ecol Biogeogr 15: $321-327$

Rilov G, Dudas SE, Menge BA, Grantham BA, Lubchenco J, Schiel DR (2008) The surf zone: a semi-permeable barrier to onshore recruitment of invertebrate larvae? J Exp Mar Biol Ecol 361:59-74

Sarda R (1991) Polychaete communities related to plant covering in the mediolittoral and infralittoral zones of the Balearic Islands (western Mediterranean). PSZNI: Mar Ecol 12:341-360

Serrano A, Preciado I (2007) Environmental factors structuring polychaete communities in shallow rocky habitats: role of physical stress versus habitat complexity. Helgol Mar Res 61:17-29

Sokal RR, Oden NL (1978) Spatial autocorrelation in biology. 1. Methodology. Biol J Linn Soc 10:199-225

Srivastava DS, Lawton J (1998) Why more productive sites have more species: an experimental test of theory using tree-hole communities. Am Nat 152:510-529

Stevens CL, Taylor DI, Delaux S, Smith MJ, Schiel DR (2008) Characterisation of wave-influenced macroalgal propagule settlement. J Mar Syst 74:96-107

Tena J, Capaccioni-Azzati R, Torres-Gavila FJ, Garcia-Carrascosa AM (2000) Polychaetes associated with different facies of the photophilic algal community in the Chafarinas archipelago (SW Mediterranean). Bull Mar Sci 67: 55-72

> ter Braak CJF (1986) Canonical correspondence analysis: a new eigenvector technique for multivariate direct gradient analysis. Ecology 67:1167-1179

ter Braak CJF (1987) CANOCO: a FORTRAN program for canonical community ordination by partial detrended canonical correspondence analysis, principal components analysis and redundancy analysis (version 2.1). Agricul- 
ture Mathematics Group, Wageningen

The Medatlas Group (2004) Wind and Wave Atlas of the Mediterranean Sea. Western European Armaments Organization (WEAO) Research Cell

Ward TJ, Vanderklift MA, Nicholls AO, Kenchington RA (1999) Selecting marine reserves using habitats and species assemblages as surrogates for biological diversity. Ecol Appl 9:691-698
Warwick RM, Clarke KR (1993) Increased variability as a symptom of stress in marine communities. J Exp Mar Biol Ecol 172:215-226

Wright DH (1983) Species-energy theory, an extension of species-area theory. Oikos 41:496-506

Young CM, Cameron JL (1989) Differential predation by barnacles upon larvae of two bryozoans: spatial effects at small scales. J Exp Mar Biol Ecol 128:283-294

Appendix 1. Site geographic locations and physical habitat descriptors. Exposure is expressed as cosine of angle between the coastline and the wave $(0=$ site is sheltered; values approaching 1 = coast is orthogonal to wave direction and wave exposure is maximum)

\begin{tabular}{|c|c|c|c|c|c|c|c|c|c|c|}
\hline & Pontetto & $\begin{array}{c}\text { Punta } \\
\text { Chiappa } \\
\text { west }\end{array}$ & $\begin{array}{c}\text { Punta } \\
\text { Chiappa } \\
\text { east }\end{array}$ & Portofino & Framura & Bonassola & Levanto & Monterosso & Montenero & Monesteroli \\
\hline \multicolumn{11}{|l|}{ Site scale } \\
\hline Latitude $\left({ }^{\circ} \mathrm{N}\right)$ & 44.375895 & 44.322628 & 44.322624 & 44.30191 & 44.199593 & 44.180267 & 44.139323 & 44.133577 & 44.093557 & 44.075682 \\
\hline Longitude $\left({ }^{\circ} \mathrm{E}\right)$ & 9.075364 & 9.14528 & 9.146108 & 9.216081 & 9.555486 & 9.574471 & 9.627153 & 9.635771 & 9.738201 & 9.774824 \\
\hline Distance from Recco (m) & 5400 & 4205 & 4250 & 9000 & 37700 & 40100 & 46000 & 46900 & 56200 & 59740 \\
\hline Distance from Rapallo (m) & 12740 & 7210 & 7170 & 5100 & 30760 & 33140 & 39300 & 40140 & 49500 & 53000 \\
\hline Distance from Entella (m) & 21640 & 14800 & 14915 & 9200 & 21750 & 24150 & 30350 & 31200 & 40500 & 44000 \\
\hline Distance from Magra (m) & 81700 & 74100 & 73960 & 67950 & 38600 & 36300 & 30700 & 29900 & 20770 & 17500 \\
\hline Fractal (GIS) & 1.18 & 1.10 & 1.03 & 1.07 & 1.05 & 1.04 & 1.01 & 1.03 & 1.02 & 1.07 \\
\hline Sinuosity (GIS) & 1.67 & 1.34 & 1.08 & 1.24 & 1.18 & 1.12 & 1.03 & 1.10 & 1.08 & 1.28 \\
\hline Sinuosity (Chain) & 1.38 & 1.25 & 1.50 & 1.79 & 1.43 & 1.21 & 1.44 & 1.60 & 1.32 & 1.41 \\
\hline Exposure (from 225) & 0.91 & 0.09 & 0.09 & 0.00 & 0.97 & 0.09 & 0.99 & 0.26 & 0.97 & 0.42 \\
\hline \multicolumn{11}{|l|}{ Within site scale } \\
\hline Slope $\left({ }^{\circ}\right)$ & 37 & 69 & 29 & 74 & 58 & 55 & 69 & 77 & 73 & 72 \\
\hline Min-Max & $0-90$ & $10-90$ & $5-70$ & $10-90$ & $5-90$ & $10-90$ & $45-90$ & $30-90$ & $0-90$ & $20-90$ \\
\hline Mean turf height (mm) & 5.3 & 5.4 & 8.1 & 7.4 & 14.3 & 11.7 & 6.3 & 7.7 & 7.5 & 5.2 \\
\hline Min-Max & $2-10$ & $3-7$ & $5-12$ & $3-16$ & $2-30$ & $5-22$ & $3-12$ & $3-12$ & $4-12$ & $3-10$ \\
\hline Mean height to barnacles (cm) & 52.1 & 61.7 & 50.1 & 60.0 & 50.0 & 65.6 & 62.3 & 44.5 & 46.0 & 52.5 \\
\hline Min-Max & $25-80$ & $58-66$ & $30-65$ & $10-90$ & $30-70$ & $52-80$ & $40-85$ & $30-60$ & $25-70$ & $30-60$ \\
\hline Turf organic content $(\mathrm{g})$ & 0.51 & 0.4 & 0.5 & 0.34 & 14.3 & 0.4 & 0.3 & 0.4 & 0.4 & 0.4 \\
\hline Min-Max & $0.1-1.8$ & $0.1-1.6$ & $0.1-1.8$ & $0-11$ & $2-30$ & $0-1.2$ & $0-0.7$ & $0-2.4$ & $0-1.1$ & $0-2.4$ \\
\hline Turf sediment $(\mathrm{g})$ & 1.35 & 1.45 & 2.64 & 1.75 & 1.17 & 1.36 & 1.81 & 1.93 & 2.82 & 2.14 \\
\hline Min-Max & $0.2-3.7$ & $0.2-4.1$ & $0.2-11.5$ & $0.2-5.1$ & $0.2-5.0$ & $0.2-3.4$ & $0.2-4.0$ & $0.6-5.6$ & $0.2-9.0$ & $0.2-7.3$ \\
\hline \multicolumn{11}{|c|}{ Functional traits (\% total no. of ind. site ${ }^{-1}$ ) } \\
\hline Low adult and larvae mobility & 44 & 28 & 32 & 35 & 22 & 25 & 16 & 26 & 18 & 13 \\
\hline Low adult and high larvae mobility & 22 & 32 & 17 & 20 & 53 & 24 & 53 & 25 & 43 & 54 \\
\hline High adult and larval mobility & 12 & 18 & 25 & 18 & 5 & 23 & 17 & 26 & 21 & 22 \\
\hline Deposit feeder & 7 & 8 & 14 & 8 & 7 & 11 & 7 & 10 & 9 & 9 \\
\hline Grazers & 37 & 25 & 25 & 23 & 20 & 30 & 16 & 24 & 18 & 15 \\
\hline Predators & 31 & 24 & 40 & 39 & 17 & 32 & 17 & 26 & 23 & 16 \\
\hline Suspension feeders & 24 & 43 & 22 & 31 & 55 & 27 & 60 & 38 & 50 & 60 \\
\hline
\end{tabular}

Editorial responsibility: Lisandro Benedetti-Cecchi, Pisa, Italy
Submitted: August 12, 2010; Accepted: November 25, 2010 Proofs received from author(s): February 16, 2011 